This is an electronic reprint of the original article. This reprint may differ from the original in pagination and typographic detail.

Author(s): Hietalahti, Merja; Tolvanen, Asko; Kokko, Katja

Title: $\quad$ Values and Personal Life Investment in Middle-Age: Measures and Relations

Year: $\quad 2015$

Version:

Please cite the original version:

Hietalahti, M., Tolvanen, A., \& Kokko, K. (2015). Values and Personal Life Investment in Middle-Age: Measures and Relations. Journal of Adult Development, 22(4), 206220. https://doi.org/10.1007/s10804-015-9212-7

All material supplied via JYX is protected by copyright and other intellectual property rights, and duplication or sale of all or part of any of the repository collections is not permitted, except that material may be duplicated by you for your research use or educational purposes in electronic or print form. You must obtain permission for any other use. Electronic or print copies may not be offered, whether for sale or otherwise to anyone who is not an authorised user. 


\title{
Values and Personal Life Investment in Middle-Age: Measures and Relations
}

\author{
Merja Hietalahti, Asko Tolvanen \& Katja Kokko. University of Jyväskylä, Finland
}

Author note

${ }^{1}$ Merja Hietalahti, ${ }^{1}$ Asko Tolvanen $\&{ }^{2}$ Katja Kokko. ${ }^{1}$ Department of Psychology, University of Jyväskylä, Finland. ${ }^{2}$ Gerontology Research Center and Department of Health Sciences, University of Jyväskylä, Finland. Correspondence concerning this article should be addressed to Merja Hietalahti, University of Jyvaskyla, Department of Psychology, P.O. Box 35, FI-40014 University of Jyvaskyla, Finland. Telephone: +358 440358289, e-mail: merja.a.hietalahti@jyu.fi. 


\section{Abstract}

The present study analyzed the factor structure of Schwartz Value Survey (SVS; 46 items) and the Personal Life Investment (PLI; 10 items) scale, as well as the mutual relations between these two measures. The 50-year-old participants $(n=217$ to 224$)$ were drawn from the ongoing Finnish Jyväskylä Longitudinal Study of Personal and Social Development. For the SVS, the Confirmatory Factor Analysis (CFA) supported the 14-factor structure: achievement, tradition, stimulation, hedonism, security, conformity, power, universalism (with sub-factors of societal concern, tolerance and protecting nature), benevolence (with sub-factors of caring and dependability) and self-direction (with sub-factors of autonomy of action and autonomy of thought). Using these 14 factors, the CFA confirmed the existence of higher-order factors with both two (person-focused and social-focused dimensions) and four factors (self-transcendence, self-enhancement, conservation and openness to change). In assessing personal life investments, three factors emerged using CFA: soul-searching (items of cognition, independence, life reflection and death), basic needs (sexuality, family and work) and pleasure (health, leisure and friends). The three PLI factors and 14 SVS items related to each other in some ways. For example, soul-searching correlated statistically significantly and positively with all three of universalism's sub-factors (societal concern, tolerance, and protecting nature). Basic needs correlated positively with achievement and benevolence (dependability). Finally, pleasure correlated positively, for example, with benevolence (caring), and hedonism.

Keywords: values; personal life investment; factor structure; middle-age 


\section{Introduction}

Values and personal life investment (PLI) are important constructs of evaluating adults' life quality issues. Values are grounded in one or more of three universal requirements of human existence: 1) individuals needs as a biological organism; 2) need for coordinated social interaction; and 3) society's survival and welfare needs (Schwartz and Bilsky 1990; Schwartz 1992, 1994, 2007; Schwartz et al. 2012). Values can work as guiding principles in an individual's life (Caprara et al. 2003; Schwartz 1992). PLI, instead, is a concept that measures the motivational intensity during goal striving or, more specifically, the amount of energy and effort that people report investing in central life domains (e.g., health and family) (Schindler 2005; Schindler et al. 2006; Schindler and Staudinger 2008; Staudinger and Fleeson 1996; Staudinger et al. 1999). Personal life investment has been assessed using a measure developed by Staudinger (see, e.g., Staudinger and Fleeson 1996), while values have commonly been assessed using the Schwartz Value Survey (SVS). Few studies have analyzed the factor structures of the PLI and SVS scales, particularly the refined version of the latter using 19 fine-tuned values (e.g., Schindler and Staudinger 2008; Schwartz and Boehnke 2004; Schwartz et al. 2012), and there are no studies that have investigated the mutual relations between Schwartz values and Staudinger's personal life investment items. In the present study, we examined the factor structures used to assess Schwartz values (e.g., Schwartz 1992; Schwartz et al. 2012) as well as those used in measuring personal life investment (e.g., Staudinger and Fleeson 1996; Staudinger et al. 1999); in doing so, we also investigated mutual links between the factors and items of these two measures, examined specifically in regard to a sample of fifty-year-old Finnish research participants. 
Individual values have many different definitions in the literature. However, there are five features that are common to most of the life value definitions: a value is seen as a 1) belief, 2) pertaining to desirable behaviors that 3) prevail in different kinds of situations, 4) guide the selection or evaluation of behavior, people, and events, and 5) is prioritized by relative importance (e.g., Allport 1961; Maslow 1959; Rokeach 1973; Schwartz 1992, 1994; Schwartz and Bilsky 1987, 1990). Values are a central aspect of culture and a crucial issue that explains cross-cultural differences in individual's behavior (e.g., Smith and Schwartz 1997). In the present study, we define values in terms of functioning as a guiding principle (nouns represent terminal values, such as inner harmony) or being reflected in a course of action (adjectives represent instrumental values, such as ambitious) in an individual's life (e.g., Schwartz 1992).

Moreover, values have been classified in several ways. Schwartz (e.g., Schwartz 1992, 1994) has identified ten motivationally different values, which form a motivational continuum; these ten values were investigated in the current study: power (e.g., social status and reputation), achievement (e.g., personal success), hedonism (e.g., pleasure and sensuous gratification for oneself), stimulation (e.g., excitement and novelty), self-direction (e.g., independent thought and action), universalism (e.g., appreciation, tolerance and protection for the welfare of people and nature), benevolence (e.g., preservation and enhancement of the welfare of people with whom one is frequently in contact), tradition (e.g., commitment of the customs and ideas that traditional culture or religion provide the self), conformity (e.g., inhibition of actions or impulses likely to harm others), and security (e.g., safety and harmony of society, relationship, and self). Based on his theory, Schwartz (1992) has developed a values measure named Schwartz Value Survey (SVS), aiming to explain a considerable amount of the variation in specific attitudes and behaviors between individuals (Datler et al. 2013). The measure's ten basic values have also 
been suggested to be of relevance in over 60 countries (Schwartz 1992, 1994; Schwartz and Sagiv 1995). Still, discussions continue on the degree of cross-cultural meaning equivalence concerning the items featured in the SVS (Davidov 2008; Davidov et al. 2008; Fischer 2012; Knoppen and Saris 2009).

The ten individual values can be attributed to two theory-based dimensions (personfocused and social-focused) (Schwartz 2006; Fontaine et al. 2008) formed on the basis of four higher-level values: self-transcendence (universalism, benevolence), self-enhancement (power, achievement), openness to change (self-direction, stimulation), and conservation (security, conformity, and tradition) (Fontaine et al. 2008; Schwartz and Boehnke 2004). Selftranscendence highlights the acceptance of other people and concern for their well-being. This value category conflicts with self-enhancement, which highlights aiming at ones success and dominance. Openness to change underlines independence of thought, action and emotion. These values conflict with conservation, which protects traditional practices and stability. Hedonism belongs to the openness to change and self-enhancement categories (Schwartz and Boehnke 2004; Schwartz 2005), but is usually closer to openness to change (in about two-thirds of samples) (Schwartz 2006; Schwartz et al. 2012). The social-focused dimension includes selftranscendence and conservation, which regulate relations with others. Instead, the personfocused dimension includes openness to change and self-enhancement, which regulate the expression of personal interests (Fontaine et al. 2008; Schwartz 2006). Study by Fontaine et.al. (2008) concluded that the two-dimensional aspect of Schwartz's Theory of Basic Values forms an adequate model (based on metric multidimensional scaling analyses in SAS) and value structure for researching structural equivalence of the values across cultures. 
Schwartz and his colleagues (2012) have recently refined the theory of basic human values. In the revised theory, they presented a new instrument with 19 fine-tuned, conceptually distinct values (universalism-societal concern, universalism-tolerance, universalism-nature, benevolencecaring, benevolence-dependability, self-direction-thought, self-direction-action, stimulation, hedonism, achievement, power-resources, power-dominance, face, security-personal, securitysocietal, tradition, conformity-rules, conformity-interpersonal, humility) which includes all the essential components of the original 10 values.

Furthermore, values have been classified as being either intrinsic (e.g., connections to other people) or extrinsic (e.g., reputation) by nature (Deci and Ryan 1995; Kasser and Ryan 1993; Ryan et al. 1999; Schmuck et al. 2000). Intrinsic values have been shown to be identical in meaning with Schwartz and Bilsky's (1987) self-direction, benevolence, conformity and universalism values. Allport and Vernon (1931) have categorized, for their part, six different value types: political, social, economic, theoretical, religious and aesthetic values. In Rokeach’s (1973) extensively used 36-item value survey (Rokeach Value Survey, RVS), there are 18 terminal values (e.g., wisdom) and 18 instrumental values (e.g., capable) (Feather 1975; Lovejoy 1950; Rescher 1969; Rokeach 1973; Rokeach and Ball-Rokeach 1989). Values have also often been classified as individualistic (e.g., pleasure) versus collective (e.g., equality) values (Schwartz and Bilsky 1990). Some values are both individualistic and collective, such as wisdom. Since there is currently no unified classification system in use for research on values, it is difficult to compare different research results on the topic (Roberts and Robins 2000). While the SVS has been the most widely used value instrument over the past two decades, the refined version featuring 19 itemized values (Schwartz et al. 2012) has not been critically assessed. 
Another concept related to values is Staudinger's measure of Personal Life Investment (PLI), assessing the amount of energy and effort that people report to be investing in central life domains (e.g., sexuality and independence) (e.g., Schindler 2005; Schindler et al. 2006; Schindler and Staudinger 2008). Staudinger developed the Personal Life Investment questionnaire to assess so-called 'optional' and 'obligatory' personal life investments. Obligatory life investments are things that people must do, whereas optional life investments are things that people can choose to do. The conceptualizing of obligatory personal life investments as representing a "must" means that this category is comprised only of investments that an individual absolutely needs to make, regardless of their desire or control.

We are not aware of any previous studies that have investigated the structure of the PLI measure with data other than the Berlin Aging Study (Baltes and Mayer 1999), which examined a group of 70-103-year-old individuals. In the present study, the obligatory personal life investments investigated are health, cognitive fitness, well-being of family members, independence, thinking about one’s life and death (e.g., Schindler et al. 2006). Instead, optional personal life investments examined are hobbies and interests, friends and acquaintances, sexuality, and occupation or work-related activities. Each of the ten PLI items should be viewed as scales of their own that measure investment in a specific life domain. Every rating of a personal life investment reflects positive (e.g., planning and making progress toward goals) and negative (e.g., worrying and rumination) aspects of aspiration.

There are some clear differences in the contents of the obligatory versus optional personal life investment categories. Obligatory personal life investments describe individuals’ investment in life domains that represent life's basic necessities or pose age-normative challenges (Schindler 2005). In contrast, optional personal life investments represent person's investment in life 
domains that are chosen on the basis of personal interests. The PLI concept can help in understanding some of the processes that are in operation when individuals try to master life through their actions and reactions (Schindler and Staudinger 2008).

The defined personal life investments bear similarities to definitions of values. Values and personal life investments can both be seen as a form of goal orientation (e.g., Schwartz 1992; Schindler 2005). Personal life investments specifically represent goal investment and values represent motivational goals when individuals are pursuing the goals that are important to them. In previous literature, values have been seen as learned beliefs about desirable ways to behave and they can also motivate a person's action (Costa and McCrae 2001; McCrae and Costa 1999; Rohan 2000; Rokeach 1973; Schwartz 1994; Seligman et al. 1996). Individuals do not always necessarily act in a way that is in accordance with their values in every situation. People may appreciate some specific values per se, but in some situations these values may act more as background beliefs than actualizing behavior. According to Schindler and Staudinger (2008), people can think life investment domains in their everyday lives without really doing for the domains. This means that individuals invest in life to different domains, for example to life reflection or friends. Values share this aspect with personal life investments. According to Rokeach (1973), people commonly consider those kinds of values important that they are not actually living according to at the moment but want to strive for. This aspect of goal striving is present both in values (Schwartz 1992) and personal life investment (Schindler 2005; Schindler et al. 2006; Schindler and Staudinger 2008).

In the present study, the first aim was to study the SVS's factor structure in regard to a Finnish sample of 50-year-old participants (e.g., Schwartz 1994), analyzing different theorydriven models that have attained some empirical support (Fontaine et al. 2008; Schwartz and 
Boehnke 2004; Schwartz et al. 2012). We used a Finnish version of the SVS with 57 items, which included the 46-item international version of the survey (Schwartz and Boehnke 2004). We first tested whether the 10-value factor structure fitted to the data, both in regard to the 57item version and the 46-item version. Moreover, we examined the refined 19-factor version partly (Schwartz et al. 2012). Additionally, the following second-order factor models were analyzed to test the latent higher-order value factors: two-factor structure (1. person-focused: including the values of self-direction, stimulation, hedonism, achievement and power; versus 2. social-focused: including the values of universalism, benevolence, tradition, conformity and security) (Schwartz 2006); and four-factor structure (1. self-transcendence: including universalism and benevolence; 2. self-enhancement: including power and achievement; 3. conservation: including tradition, security and conformity; and 4. openness to change: including self-direction, stimulation and hedonism).

The second aim was to investigate the factor structure of the ten PLI items among the same 50-year-old participants. These ten items have previously been used along a two-factor structure (obligatory versus optional) in examining 70-103-year-old individuals (e.g., Schindler 2005; Schindler et al. 2006; Schindler and Staudinger 2008). We first tested whether these two factorial dimensions could be distinguished among the middle-aged (50-year-old) participants, while we also allowed the factors emerge naturally. We expected that the previously obtained factorial dimensions of obligatory and optional life investments might not replicate. Compared to the older participants, the middle-aged participants were more likely to be in work and, consequently, were assumed to consider work to be an obligatory rather than optional personal life investment. 
The third aim was to examine the associations between the PLI instrument's factor structure and Schwartz's factor structure of values, utilizing the models that emerged in the present research. We are not aware of any previous empirical studies on the relations between personal life investments and values. Consequently, we did not set specific hypotheses, but assumed that there would be significant associations, such as for hedonism to be positively related to leisure and friends, achievement to work and benevolence to family.

\section{Method}

\section{Participants and Procedure}

The present study was based on the ongoing Jyväskylä Longitudinal Study of Personality and Social Development (JYLS), conducted in Finland, in which the same individuals were followed up from age 8 to 50 (Pulkkinen 2006; Pulkkinen and Kokko 2010). The research was initiated in 1968 by Lea Pulkkinen when she randomly selected 12 complete second-grade classes in the town of Jyväskylä, Finland, for the study. The initial attrition was zero, that is, all the students in the 12 classes took part in the study. The initial sample consisted of 369 participants, 173 girls and 196 boys, of whom the majority were born in 1959. All participants were native Finns. From the time the participants reached age 8, the main data collections took place when the participants were 14, 27, 36, 42 and 50 years old. In the present study, the data gathered when the participants reached age 50 (in 2009) were used; that was the only age group for which the SVS was available.

The participation rate in the JYLS study has been high throughout the years and there has not been any systematic attrition (Pulkkinen 2006; Pulkkinen et al. 2003; Pulkkinen and Kokko 2010). By age fifty, 12 of the participants had died and 34 had refused to continue to take part in the study. Consequently, the sample size eligibility was reduced from 369 to 323 participants. Of 
this eligible sample, 271 participants (84\%; 127 female and 144 male) took part in at least one of the following main data collection campaigns: a life-situation questionnaire, a semi-structured psychological interview, or a health examination. At age 50, the participants who took part in the data collection represented the whole Finnish age-cohort born in 1959 according to comparisons with data provided by Statistics Finland on, for example marital status, family type, number of children, employment, and unemployment (Pulkkinen and Kokko 2010).

In the present study, the information collected when the participants were aged 50 was used, attained through a psychological interview and mailed inventory filled in and returned before the interview. 227 individuals (111 female and 116 male) participated in the psychological interview and 217 individuals (109 female and 108 male) returned the mailed questionnaire. The psychological interview included the Personal Life Investment survey (Schindler 2005; Schindler et al. 2006; Schindler and Staudinger 2008; Staudinger and Fleeson 1996) and the mailed inventory included the Schwartz Value Survey (SVS; e.g., Schwartz 1992, 1994; Schwartz and Sagiv 1995), both of which were examined in the current study. PLI scale measurement results were available for 224 participants (111 female and 113 male) of the 227 who participated in the psychological interview, and SVS results were available for all the aforementioned 217 participants having returned the mailed questionnaire.

\section{Measures}

In this study, the SVS (e.g., Schwartz 1992, 1994; Schwartz and Sagiv 1995) was examined. Martti Puohiniemi had translated the SVS into Finnish, adapting it to Finnish culture (Puohiniemi 1995; Pulkkinen and Kokko 2010) and, in general, aiming to find values that would also fit universally, with various cultures (Schwartz et al. 2011). In the adapted Finnish SVS version, there are 30 life-guiding principles (e.g., wealth) and 27 courses of action (e.g., daring) 
(Puohiniemi 1995), the personal importance of which the participants were asked to assess. Schwartz values have only been studied in regard to the 50-year-old participants in the JYLS study. We analyzed the 57 items included in the survey, and also the 46-item international version (Schwartz and Boehnke 2004) included in the 57-item version, for which respondents rated each value on a 9-point scale regarding its importance as a guiding principle in their life, from -1 = opposite to my values; $0=$ not important; $1,2,3=$ important; 4, 5, 6 = very important; 7 = extremely important; usually people have only one or two values that they consider to be extremely important to themselves.

Additionally, the PLI scale (e.g., Schindler 2005; Schindler et al. 2006; Schindler and Staudinger 2008) was used; the participants were asked to assess the amount of energy and effort that they invest nowadays, in terms of action and thought, in ten life domains: health, cognitive fitness, hobbies and interests, friends and acquaintances, sexuality, well-being of family members, occupation or work-related activities, independence, thinking about one's life, and thinking about one's death and dying (see, e.g., Schindler 2005). For each life domain, participants were asked the same question, such as: "How about your sexuality? How much do you think about it or do something about it nowadays?” Participants rated their personal life investments on a 5-point Likert-type scale, ranging from $1=$ no investment at all nowadays to 5 = very much investment nowadays.

\section{Statistical Analyses}

The primary analysis consisted of Structural Equation Modeling (SEM), using the Mplus statistical package (version 7; Muthén and Muthén 1998-2012), in which robust (against nonnormality) maximum likelihood estimation (MLR; full information maximum likelihood) was 
used. Using the MLR, the assumption is that missing values are missing at random (MAR). The SVS factor structure fitting the data best was studied using confirmatory factor analysis (CFA).

In analyzing whether the previously found (e.g., Schindler and Staudinger 2008) two-factor structure of the ten PLI items fits the present data, we used CFA. To find possible alternative models to the two-factor model that might better describe the factor structure of the present data, we also conducted exploratory factor analysis (EFA) with principal axis factoring (PAF) and direct oblimin rotation. We ran the EFA using the IBM SPSS Statistics program (version 20). Eigenvalues greater than 1 were set as a criterion in extraction. Subsequently, CFA was conducted to examine the emerging model.

For the evaluation of the fit of the alternative SVS models, we used the following goodness-of-fit indices as criteria: RMSEA (root mean-squared error of approximation), in which values <.06 indicate that the model fits the data well; and SRMR (standardized root meansquared residual) in which values <.08 indicate a good fit (Hu and Bentler 1999). Moreover, items' standardized factor loadings were observed in the model selection process. In evaluating the PLI items' fit with the EFA model in CFA, we used several goodness-of-fit-indices: the aforementioned RMSEA and SRMR indices with the same criteria (Hu and Bentler 1999); a chisquared value with $p>.05$ representing a good fit of the model with the data (Bollen 1989); and the Tucker-Lewis Index (TLI; Tucker and Lewis 1973) and Comparative Fit Index (CFI; Bentler 1990) to evaluate the model fit, where values above .95 represent a good fit of the model to the data (Hu and Bentler 1999). Our final set of SEM analyses concerned the correlations between the SVS and PLI measures' factors. 


\section{Results}

\section{Descriptive Results}

Table 1 shows the means and standard deviations for the 57 items of the Schwartz Value Survey (SVS). The three most important values were family security, inner harmony and honesty. In contrast, the three least important values were social power, devout and authority. The Schwartz values showed several statistically significant correlations at the item-level. Correlations were between -.12 (family security with curious) and .60 (devout with spiritual life).

Insert Table 1 about here

Table 2 indicates the means and standard deviations for the ten items of the Personal Life Investment measure. Participants mostly considered the well-being of family members to be of greatest importance, and health was in second place. One's death was the least thought about domain. There were several statistically significant correlations between the PLI items. The highest correlations were between health and leisure (.41) and between independence and life reflection (.39). In addition, the lowest correlation was between family and death (-.09), and secondly, between work and death (-.09). Overall, the correlations ranged from -.09 to .41. Insert Table 2 about here

\section{Structural Equation Modeling (SEM) and Confirmatory Factor Analyses (CFA)}

Table 3 shows the three alternative models for the different SVS versions tested using CFA: 1) the 57-item Finnish version with 10 value factors; 2) the 46-item international version (all 46 items were extracted from the 57-item version) with the same 10 value factors; 3) a model of 14 fine-tuned value factors using the 46-item version. Because the 10 factors did not describe the 46-item version sufficiently well, we performed a separate one-factor analysis of each one of the 10 value factors; based on the results, the universalism, benevolence, security and self-direction 
factors needed some modification concerning the model fit indices. In the analyses that followed, for those four factors, we used the fine-tuned values' sub-factors (Schwartz et al. 2012): universalism (societal concern, tolerance, protecting nature), benevolence (caring and dependability), security (personal and societal), and self-direction (autonomy of thought, and autonomy of action). We found that dividing security into two sub-factors did not improve the fit compared to measuring the security factor without sub-factors. However, dividing universalism, benevolence and self-direction into sub-factors did improve the fit. As Schwartz et al. (2012) mentioned, the item for freedom is ambiguous, because it implies both the freedom of thought and action. So, we set this item to load on both of the sub-factors of self-direction (i.e., autonomy of thought, and autonomy of action).

In selecting the best-fitting model, the following aspects were taken into consideration: the goodness-of-fit of the model and sufficiently high standardized factor loadings. The RMSEA of the null model of the selected model was 0.123 . We used only RMSEA and SRMR in selecting the best model. This is in line with Kenny's (2014) following argument: "this mathematical fact, that a model whose null model RMSEA is less than 0.158 and whose RMSEA is 0.05 must have a TLI of less than .90 is something that has never been published but is in fact true". The RMSEA and SRMR indices and standardized factor loadings for the tested models are shown in the Table 3. The selected model's RMSEA was .05 and the SRMR was .07, both indicating a good model fit with the data. The first-order factor loadings occurred between .40 and .84 . Lower factor loadings occurred only with two items: the security factor's item of family security was .27 and the self-direction factor's two sub-factor ambiguous items of freedom were .26 (autonomy of action) and .28 (autonomy of thought). All loadings were statistically significant $(p<.001)$, except the freedom item. 
The Cronbach's alphas of the SVS instrument's 14 value factors were estimated to test the reliabilities of the obtained factors. The alphas were as follows (sub-factors are in parentheses): universalism (societal concern) .70, universalism (tolerance) .48, and universalism (protecting nature) .73; benevolence (caring) .69, benevolence (dependability) .62; self-direction (autonomy of action) .49, self-direction (autonomy of thought) .65; security .59; conformity .77; tradition .63; power .72; hedonism .78; stimulation .74, and achievement .83. The correlations between factors ranged from .08 to .96. The lowest correlations were between stimulation and benevolence (dependability) .08, and second lowest between power and universalism (tolerance) .09. In addition, highest correlations were between security and conformity .96, and second highest between self-direction (autonomy of thought) and universalism (tolerance) .91. Insert Table 3 about here

Table 4 shows two alternative second-order factor models in comparison: 1) the secondorder theory-driven model of two factors including person- and social-focused dimensions, and 2) the second-order factor model of four values: conservation, openness to change, selftranscendence, and self-enhancement. The second-order factor's loadings were relatively high (.51 to .99). This means that the 14-values factor model (self-direction with its two sub-factors of autonomy of thought and autonomy of action, stimulation, hedonism, achievement, power, security, tradition, conformity, benevolence with its two sub-factors of dependability and caring, universalism with its three sub-factors of societal concern, tolerance and protecting nature), as a latent higher-order factor model of the SVS, supported the theory-based second-order two(person- and social-focused) and four-factor (conservation, self-enhancement, selftranscendence, and openness to change) solutions. In the second-order four factor model, the correlations between factors ranged from .41 (self-transcendence with self-enhancement) to .82 
(self-transcendence with conservation). In the second-order two factors model, the correlation between person-focused and social-focused factors was .59. Hedonism fitted equally well with both openness to change and self-enhancement higher order factors according to the RMSEA (.06) and SRMR (.08) fit-indices. In the current study, hedonism is in the openness to change higher order factor because of slightly higher correlations to openness to change versus selfenhancement factor, this support the main part of the previous studies (in about two-thirds of samples) (Schwartz 2006; Schwartz et al. 2012).

Insert Table 4 about here

The CFA results show that the PLI measure's two-factor structure (optional and obligatory) did not fit the data sufficiently well with respect to the relationships between the ten items (Table 5). The fit indices were as follows: $\chi^{2}(34)=87.62, p=.000$, RMSEA $=.08$, SRMR $=.08$, CFI $=.74$ and TLI $=.65$. Additionally, the work item's loading was not statistically significant in connection with the optional factor. The CFA analyses were followed by an EFA, the results of which were confirmed by CFA. The standardized factor loadings of the selected PLI model are shown in Table 5. The factor loadings ranged from .34 to .80 and were all statistically significant. In the selected PLI model, there were three factors and 3-4 items for each factor. The first factor was named soul-searching. It consisted of cognition, independence, life reflection, and death items. The second factor was named basic needs and included sexuality, family, and work. Finally, the third factor was labeled pleasure. It included the items health, leisure, and friends. All of the fit indices indicated that the selected model fit the data sufficiently well. The goodness-of-fit indices were as follows: $\left(x^{2} 31, n=224\right)=41.08, p=.107$, RMSEA $=$ $.04, \mathrm{SRMR}=.06, \mathrm{CFI}=.95$ and TLI $=.93$. The Cronbach's alphas were estimated to test the reliabilities of the three factors. The alpha for soul-searching was .64 , for basic needs .45 , and for 
pleasure .56. The standardized correlations between the PLI factors were as follows: soulsearching with basic needs .19; pleasure with soul-searching .68; and pleasure with basic needs .43.

Insert Table 5 about here

As the final step, we analyzed the correlations of the SVS's 14 value factors and the PLI's three factors using CFA (Table 6). As can be seen in Table 6, there were several statistically significant correlations between the two surveys' factors (sub-factors are shown in parentheses). Overall, the correlations ranged from -.01 for soul-searching with benevolence (dependability) to .30 for basic needs with achievement. Soul-searching correlated with all three of universalism’s sub-factors - societal concern (.29), tolerance (.26), and protecting nature (.22). Further, basic needs correlated with achievement (.30) and benevolence (dependability) (.28). Additionally, pleasure correlated with universalism (protecting nature) (.24), benevolence (caring) (.26), and hedonism (.26). Thus, these results supported the expected item-level associations.

Insert Table 6 about here

Table 7 shows the correlations of the PLI measure's three factors with the SVS's secondorder two- and four-factor models, using SEM. Self-transcendence correlated statistically significantly with soul-searching (.21) and pleasure (.27). Openness to change correlated with pleasure (.30). Moreover, the person-focused factor correlated with pleasure (.23). Insert Table 7 about here

\section{Discussion}

The present study focused on Schwartz values and PLI scale factor structures, as well as their mutual relations among a selected sample of 50-year-old Finnish participants. Regarding values, the current research did not fully support the 10-factor structure; instead, the model with 14 value 
factors fitted the present data best. These 14 values were tradition, security, power, achievement, stimulation, conformity, hedonism, universalism (with its three sub-factors called societal concern, protecting nature and tolerance), benevolence (with its two sub-factors labeled caring and dependability) and self-direction (with its two sub-factors called autonomy of thought and autonomy of action). Additionally, the present study affirmed second-order two- and four-factor models, representing relatively high standardized factor loadings. The 14 value factors determined are consistent with person- and social-focused dimensions and four higher order types of values. Consequently, the present analyses give support to the Schwartz Theory of Basic Values (e.g., Schwartz 1992; Schwartz et al. 2012).

In general, the loadings of the SVS items were relatively high; only the loadings of the family security item of the security factor and the freedom item of the two self-direction subfactors (autonomy of thought and autonomy of action) were lower. One reason for the lower loading of family security may be that it did not correlate with the reciprocation of favors item under the security factor. All the other security factor's items correlated statistically significantly with each other. Family security is an essential value among the middle-aged, as shown by its ranking as the most important value according to the 50-year-old participants of the present study. As Schwartz et al. (2012) have argued, the freedom item is ambiguous because it represents both autonomy of thought and autonomy of action. In the present study, we decided to refine the freedom item by splitting it into two self-direction sub-factors (autonomy of thought and autonomy of action), because it is then fully theory-driven and the model as a whole still fitted sufficiently well with the data.

As expected, the PLI measure's factor structure yielded different results regarding the present study’s 50-year-old participants in comparison to another study’s 70-103-year-olds (e.g., 
Schindler and Staudinger 2008; Staudinger et al. 1999). Among the sample of the older participants, two factors labeled optional and obligatory were distinguishable. The main difference between the present and earlier study was that for the participants aged 50, the work item's loading with respect to the optional factor was not statistically significant. Additionally, the fit indices did not fully support the two-factor model's fit with the data. Three-factor model best described the PLI measure's structure in regard to the 50-year-old participants. In the selected model, three factors each included 3-4 items. The first factor was named soul-searching and consists of cognition, independence, life reflection, and death. The second factor was titled basic needs and includes sexuality, family, and work. Finally, the third factor was labeled pleasure and includes the items health, leisure, and friends. What can be considered to be obligatory demands varies between ages to some extent.

The three factors that emerged with respect to the 50-year-old participants in the present study represent the three different kinds of life investment domains of middle-aged individuals. Soul-searching is a mental dimension including issues (e.g., death) that may require deep thinking and finding a personal decision about one's view of life. Soul-searching shares some similarities with self-direction and person-focused dimensions of the SVS as well as with the optional dimension of personal life investments as the focus there is on the individual's autonomy of thought and personal interests, and, moreover, they are things that people can do (optional) but do not have to do (obligatory). In addition, soul-searching is related to the spirituality value, and according to Schwartz (1994) represents the goal of finding meaning in life (e.g., meaning in life, inner harmony). In midlife, people tend to evaluate their past and consider what comes next and needs to be done in the future (Lachman 2004). 
The basic needs factor represents central issues in middle-aged adult's lives, such as family and work (Lachman 2004; Pulkkinen and Kokko 2010, chapter 1). Fifty is generally considered to be a prime working age and many of 50-year-olds have their own family (spouse and/or children). In the present sample, about three-fourths had a partner and over $80 \%$ had at least one child. Moreover, about four-fifths were in work (Pulkkinen and Kokko 2010). Sexuality is also important and plays a crucial part in middle-aged adults' lives, especially for individuals who have a partner (e.g., Ford and Chamratrithirong 2012; Gott and Hinchliff 2003). The family welfare item of the basic needs factor is similar in content to benevolence, which focuses on the enhancement of the welfare of people with whom one is in frequent personal contact. In contrast, the work item is more closely related to achievement, which emphasizes social status and prestige (Schwartz 1992). In addition, the basic needs items family and work resemble obligatory personal life investments (e.g., Staudinger and Fleeson 1996; Schindler et al. 2006) in content, as investing in family and work involves age-normative challenges and demands, while the basic needs item representing sexuality is more strongly related to optional than obligatory personal life investments, since investing in sexuality offers opportunities for expressing personal desires (e.g., Staudinger and Fleeson 1996; Schindler et al. 2006).

The PLI factor termed pleasure consists of the items that increase well-being, namely: health, hobbies, and friends. For example, physical health, cultivation of hobbies, and social participation are positively associated to mental well-being (Beiser 1974), and, moreover, positive social relationships are related positively to overall well-being (Kasser and Ryan 1993; Markus et al. 2004; Ryan et al. 1999; Ryff 1989; Schmuck et al. 2000). Pleasure shares a lot of similarities with hedonism, since pleasure items are hedonistic life domains. Further, the pleasure factor item labeled friends and acquaintances bears similarities to intrinsic values, which 
describe relations between people. Also, all three factors of the PLI measure share some elements with both terminal and instrumental values (Rokeach 1973). As a whole, the three PLI factors determined include many elements that are similar to the items of various value measures (e.g., Rokeach 1973; Schindler and Staudinger 2008; Schwartz 1992), but they also represent some unique elements.

Theoretically, it has been stated that values share similarities with attitudes, interests, motivation, needs, thoughts and valence concepts, or that these concepts reflect at least some value aspects (Schwartz and Bilsky 1990). These concepts are closely related to the PLI concept as well. The concepts of values, goals, aspirations, personal life investments, and life's central or important domains thus share similarities. Theories of values help in understanding the differences between individuals and cultures. Schwartz's (e.g., Schwartz 1992; Fontaine et al. 2008) theory-driven values are universal. His refined version of the values (Schwartz et al. 2012) gives researchers new possibilities through more specific sub-factor values to study various issues concerning human behavior.

The present study shows that Schwartz's 14 value factors (Schwartz et al. 2012) and the PLI measure's (Staudinger and Fleeson 1996; Staudinger et al. 1999) three factors have some relations, as was expected. Based on the CFA and SEM analyses, there were some statistically significant correlations between the two surveys. Soul-searching correlated positively with all three sub-factors of universalism, and also with self-transcendence. On the other hand, basic needs correlated positively with achievement and the dependability sub-factor of benevolence. In addition, pleasure correlated positively, for example, with hedonism and the caring sub-factor of benevolence, and, moreover, with the second-order model's self-transcendence and openness to 
change, as well as with the person-focused dimension. Thus, the expected item-level associations obtained support.

The SVS' values and the PLI scale’s items of health, hobbies, and friends (pleasure factor) share the most similarities. It may be speculated that one of the universal human requirements relating to values is the need for coordinated social interaction (Schwartz and Bilsky 1990; Schwartz 1992, 1994, 2007; Schwartz et al. 2012) and the pleasure factor reflects this with the item friends and acquaintances. Doing something for the sake of social interaction, one aspect of values, is quite similar in terms of aspiration to the PLI measure's domain of investing in friendships. Such findings support the theoretical notion that values and personal life investment share some similarities as a concept, such as the aspect of goal orientation (e.g., Schwartz 1992; Schindler 2005) or goal striving which is related both to values (Schwartz 1992) and personal life investment (Schindler 2005; Schindler et al. 2006; Schindler and Staudinger 2008) and now, also showed sharing some similarities empirically. However, further studies are needed to confirm these results with other data.

The present research has several strengths. One strength of the present study is the advanced statistical methodologies used, such as CFA and SEM. Secondly, participants in the JYLS have been reported to be representative of the Finnish age cohort born in 1959 (Pulkkinen 2006; Pulkkinen and Kokko 2010), so these results can be generalized at least with respect to 50year-old Finnish middle-aged adults. It is worth mentioning that the JYLS study results have previously been compared to, for example, US and British studies, and similarities have been found concerning many different themes such as aggression and its consequences (e.g., Dubow et al. 2006; Kokko et al. 2012), alcohol use (Pitkänen et al. 2012), and the timing of life events (Räikkönen et al. 2012). Thirdly, to the best of our knowledge, this study was the first to 
investigate the refined theory of the SVS's sub-factors in using its older version, the relevance of the PLI measure's factor structure regarding middle-age adults, and the mutual relations of these two scales.

However, we recognize that the current study is also subject to some limitations. The first limitation is that the sample size was relatively small, taking into account the great number of variables. Due to the rather small sample size, we could not analyze the factor structures and mutual relations separately for the female and male participants. The replication of the present results and the role of gender are thus suggested for future studies.

In future studies, it would also be worthwhile to study the PLI scale's structure and its factors' associations to the Schwartz values in relation to different cultures. Previously, it has been observed that there are clear and stable differences concerning the prioritization of different values in different cultures (Schwartz 1999). For instance, autonomy is quite important to most Germans but not at all to most of the people of Nepal. Additionally, in Sweden and Finland most people consider harmony and egalitarianism to be important personal values, but not so in China. However, more studies on middle-aged adults are needed to first replicate the presently suggested enhanced factor structure of the PLI scale before using it to examine other contexts. Furthermore, it would also be fruitful to study the PLI scale’s factor structure longitudinally as well as separately for men and women. It would be important to investigate the PLI measure's structure in regard to its relevance across the adult life span in order to gain more information about its sensitivity to the changing developmental contexts and demands that individuals typically experience during their consecutive life stages (Schindler 2005). Additionally, further research could investigate the associations of the PLI scale's factors and 19 newly defined Schwartz values to behavior. 


\section{Conclusions and implications}

I would like to offer three concluding points. Firstly, the results supported the theory-based factor structure of the SVS. Secondly, the PLI scale was found to require a somewhat different factor structure for 50-year-olds than had previously been applied to individuals aged 70 or above (e.g., Schindler and Staudinger 2008). Finally, the results indicated that the SVS and PLI measures have some similarities in terms of their dimensions. For future studies, it is recommended that both of these measures be used in assessing issues related to individuals’ life quality, attitudes and behavior.

The findings of the current study have several theoretical and practical implications. Firstly, they shed light on the life values and investments of middle-aged people, which have been under-studied in this area. They reveal the structure of the values and life investments and also their mutual associations. The findings suggest that three of the 10 basic human values universalism, benevolence and self-direction - should be partitioned to more narrowly defined subtypes. The results also show that there are three central life investment domains (soulsearching, basic needs and pleasure) that are specific to middle-aged adults. Secondly, the study of the relationships between values and PLI is relevant for the evaluation of the measures' validity; in other words, whether similar life domains are salient for middle-aged people assessed using different types of measures. This research provides new information about the links between personal values and life investment domains; that is, how action and thoughts (PLI) are linked with the values or vice versa. The present analyses show, for example, that if an individual prioritizes the subtypes of universalism known as societal concern, tolerance and protecting nature, he or she also seems to do something about that by investing in soul-searching. Conversely, if a middle-aged individual considers person-focused values to be important, he or 
she is likely to invest in pleasure. Thirdly, a better understanding of the structures of human values and life investments and their mutual connections is important in practice, both at the individual and organizational levels. Supporting individuals in, for example, the occupational health care sector to recognize their values and live according to them might pave the way for enhanced well-being and working ability.

\section{Acknowledgments}

The preparation of this article was funded by the Academy of Finland through grants (118316 and 135347) awarded to Katja Kokko. We appreciate Professor Lea Pulkkinen's contribution to the Jyväskylä Longitudinal Study of Personality and Social Development (JYLS) over the years, and the Academy of Finland's grant (127125) awarded to her for the most recent data collection of the Jyväskylä Longitudinal Study of Personality and Social Development in 2009.

\section{References}

Allport, G. W., \& Vernon, P. E. (1931). A Study of Values. Houghton Mifflin, Boston. MA.

Allport, G. W. (1961). Pattern and growth in personality. New York: Holt, Rinehart \& Winston.

Baltes, P. B., \& Mayer, K. U. (Eds.). (1999). The Berlin Aging Study: Aging from 70 to 100. New York: Cambridge University Press.

Beiser, M. (1974). Components and correlates of mental well-being. Journal of Health and Social Behavior, 15, 320-327.

Bentler, P. M. (1990). Comparative fit indexes in structural models. Psychological Bulletin, 107, 238-246.

Bollen, K. A. (1989). Structural equations with latent variables. New York: Wiley.

Caprara, G. V., Caprara, M., \& Steca, P. (2003). Personality’s correlates of adult development and aging. European Psychologist, 8, 131-147. 
Costa, P. T. Jr., \& McCrae, R. R. (2001). A theoretical context for adult temperament. In T. D. Wachs, \& G. A. Kohnstamm (Eds.), Temperament in context, (pp. 1-21). Mahwah, NJ: Erlbaum.

Datler, G., Jagodzinski, W., \& Schmidt, P. (2013). Two theories on the test bench: Internal and external validity of the theories of Ronald Inglehart and Shalom Schwartz. Social Science Research, 42, 906-925.

Davidov, E. (2008). A cross-country and cross-time comparison of the human values measurement with the second round of the European Social Survey. Survey Research Methods, 2, 33-46.

Davidov, E., Schmidt, P., Schwartz, S. H. (2008). Bringing Values Back In: The Adequacy of the European Social Survey to Measure Values in 20 Countries. Public Opinion Quarterly, 72.3, 420-445.

Deci, E. L., \& Ryan, R. M. (1995). Human autonomy: The basis for true self-esteem. In M. Kernis (Ed.), Efficacy, agency, and self-esteem (pp. 31-49). New York: Plenum.

Dubow, E. F., Huesmann, L. R., Boxer, P., Pulkkinen, L., \& Kokko, K. (2006). Middle childhood and adolescent contextual and personal predictors of adult educational and occupational outcomes: A mediational model in two countries. Developmental Psychology, 42, 937-949.

Feather, N. T. (1975). Values in education and society. New York: Free Press.

Fischer, R. (2012). Value isomorphism in the European Value Survey: Exploration of meaning shifts in values across levels. Journal of Cross-Cultural Psychology. Published online 10 July, doi: 10.1177/0022022111413276. 
Fontaine, J. R. J., Poortinga, Y. H., Delbeke, L., \& Schwartz, S. H. (2008). Structural equivalence of the Values Domain Across Cultures: Distinguishing Sampling Fluctuations From Meaningful Variation. Journal of Cross-Cultural Psychology, 39, 345 doi:10.1177/0022022108318112. http://jcc.sagepub.com/content/39/4/345.

Ford, K., \& Chamratrithirong, A. (2012). Midlife sexuality among Thai adults: Adjustment to Aging in the Thai Family Context. Sexuality \& Culture, 16, 158-171.

Gott, M., \& Hinchliff, S. (2003). How important is sex in later life? The views of older people. Social Science and Medicine, 56, 1617-1628.

Hu, L., \& Bentler, P. M. (1999). Cut-off criteria for fit indices in covariance structure analysis: conventional criteria versus new alternatives. Structural Equation Modeling, 6, 1-55.

Jöreskog, K., \& Sörbom, D. (1996). LISREL 8: User’s reference guide. Chicago, IL: Scientific Software International.

Kasser, T., \& Ryan, R. M. (1993). A dark side of the American dream: correlates of financial success as a central life aspiration. Journal of Personality and Social Psychology, 65, 410-422.

Kenny, D. A. (2014). Measuring Model Fit - in webpage http://davidakenny.net/cm/fit.htm.

Knoppen, D., \& Saris, W. E. (2009). Do we have to combine values in the Schwartz' human values scale? A comment on the Davidov studies. Survey Research Methods, 3, 91-103.

Kokko, K., Pulkkinen, L., Huesmann, L. R., Dubow, E. F., \& Boxer, P. (2009). Intensity of aggression in childhood as a predictor of different forms of adult aggression: A twocountry (Finland and United States) analysis. Journal of research on Adolescence, 19, 934.

Lachman, M. E. (2004). Development in midlife. Annual Review of Psychology, 55, 305-331. 
Lovejoy, A. O. (1950). Terminal and adjectival values. The Journal of Philosophy, 47, 593-608.

Markus, H. R., Ryff, C. D., Curhan, K., Palmersheim, K. (2004). In their own words: well-being at midlife among high school and college-educated adults. See Brim et al. 2004, (pp. 273319).

Maslow, A. H. (Ed.) (1959). New knowledge in human values. New York: Harper.

McCrae, R. R., \& Costa, P. T. Jr. (1999). A five-factor theory of personality. In L. A. Pervin \& O. P. John (Eds.), Handbook of personality: theory and research, $\left(2^{\text {nd }}\right.$ ed., pp. 139-153). New York: Guilford Press.

Muthén, L. K., \& Muthén, B. O. (1998-2012). Mplus user’s guide (Seventh edition). Los Angeles, CA: Muthén \& Muthén.

Pitkänen, T., Kokko, K., Lyyra, A-L., \& Pulkkinen, L. (2008). A developmental approach to alcohol drinking behaviour in adulthood: A follow-up study from age 8 to age 42 . Addiction, 103 (Suppl. I), 48-68.

Pulkkinen, L., Fyrstén, S., Kinnunen, U., Kinnunen, M-L., Pitkänen, T., \& Kokko, K. (2003). 40+ Erään ikäluokan selviytymistarina. [40+ A successful transition to middle adulthood in a cohort of Finns] (Rep. No. 349). Jyväskylä, Finland: Reports from the Department of Psychology, University of Jyväskylä.

Pulkkinen, L. (2006). The Jyväskylä Longitudinal Study of Personality and Social Development. In L. Pulkkinen, J. Kaprio, \& R. J. Rose (Eds.), Socioemotional development and health from adolescence to adulthood. (pp. 29-55). New York: Cambridge University Press.

Pulkkinen, L., \& Kokko, K. (2010). Keski-ikä elämänvaiheena. [Middle age as a stage of life]. Jyväskylä, Finland: Reports from the Department of Psychology, University of Jyväskylä. 
Puohiniemi, M. (1995). Values, consumer attitudes and behavior: an application of Schwartz's value theory to the analysis of consumer behavior and attitudes in two national samples. Doctoral dissertation. University of Helsinki. Department of Social Psychology.

Rescher, N. (1969). Introduction to value theory. Englewood Cliffs, NJ: Prentice-Hall.

Roberts, B. W., \& Robins, R. W. (2000). Broad dispositions, broad aspirations: the intersection of personality traits and major life goals. Personality and Social Psychology Bulletin, 26, 1284-1296.

Rohan, M. J. (2000). A rose by any name? The values construct. Personality and Social Psychology Review, 4, 255-277.

Rokeach, M. (1973). The nature of human values. New York: Free Press.

Rokeach, M., \& Ball-Rokeach, S. J. (1989): Stability and change in American value priorities. American Psychologist, 44, 775-784.

Ryan, R. M., Chirkov, V. I., Little, T. D., Sheldon, K. M., Timoshina, E., \& Deci, E. L. (1999). The American dream in Russia: Extrinsic aspirations and well-being in two cultures. Personality and Social Psychology Bulletin, 25, 1509-1524.

Ryff, C. D. (1989). Happiness is everything or is it? Explorations on the meaning of psychological well-being. Journal of Personality and Social Psychology, 57, 1069-1081.

Räikkönen, E., Kokko, K., Chen, M., \& Pulkkinen, L. (2012). Patterns of adult roles, their antecedents and psychosocial well-being correlates among Finns born in 1959. Longitudinal and Life Course Studies, 3, 211-227.

Schindler, I. (2005). Late-life development of personal life investment: The "musts” and “cans” of aging. Dresden, Germany: TUDpress (Dresden University Press), from http://www.qucosa.de/fileadmin/data/qucosa/documents/1315/1119007747095 5935.pdf. 
Schindler, I., Nesselroade, J. R., \& Staudinger, U. M. (2006). Development and structural dynamics of personal life investment in old age. Psychology and Aging, 21, 737-753.

Schindler, I., \& Staudinger, U. M. (2008). Obligatory and optional personal life investments in old and very old age: Validation and functional relations. Motivation and Emotion, 32, 2336.

Schmuck, P., Kasser, T., \& Ryan, R. M. (2000). Intrinsic and extrinsic goals: their structure and relationship to well-being in German and U.S. college students. Social Indicators Research, 50, 225-241.

Schwartz, S. H. (1992). Universals in the content and structure of values: Theoretical advances and empirical tests in 20 countries. In M. P. Zanna (Ed.), Advances in experimental social psychology, 25, (pp. 1-65). Academic Press, INC. Harcourt Brace Jovanovich, Publishers.

Schwartz, S. H. (1994). Are there universal aspects in the content and structure of values? Journal of Social Issues, 50, 19-46.

Schwartz, S. H. (1999). Cultural value differences: Some implications for work. Applied Psychology: An International Journal, 48, 23-47.

Schwartz, S. H. (2004). Mapping and interpreting cultural differences around the world. In H. Vinken, J. Soeters, \& P. Ester (Eds.), Comparing cultures: Dimensions of culture in a comparative perspective (pp. 43-73). Leiden, the Netherlands: Brill.

Schwartz, S. H. (2005). Basic human values: Their content and structure across cultures. In A. Tamayo \& J. Porto (Eds.), Valores e trabalbo (Values and work), (pp. 21-55). Brasilia: Editora Vozes. 
Schwartz, S. H. (2006). Les valeurs de base de la personne: Theorie, measures et applications [Basic human values: Theory, measurement, and applications]. Revue francaise desociologie, 42, 249-288.

Schwartz, S. H. (2007). Value orientations: measurement, antecedents and consequences across nations, In Jowell, R., Roberts, C., Fitzgerald, R., Eva, G. (Eds.), Measuring Attitudes Cross-Nationally. Lessons from the European Social Survey. Sage Publications, London, (pp. 169-203).

Schwartz, S. H., \& Bilsky, W. (1987). Toward a universal psychological structure of human values. Journal of Personality and Social Psychology, 53, 550-562.

Schwartz, S. H., \& Bilsky, W. (1990). Toward a theory of the universal content and structure of values: Extensions and cross-cultural replications. Journal of Personality and Social Psychology, 58, 878-891.

Schwartz, S. H., \& Boehnke, K. (2004). Evaluating the structure of human values with confirmatory factor analysis. Journal of Research in Personality, 38, 230-255.

Schwartz, S. H., \& Sagiv, L. (1995). Identifying culture-specifics in the content and structure of values. Journal of Cross-Cultural Psychology, 26, 92-116.

Schwartz, S. H., Puohiniemi, M., \& Puohiniemi, E. (2011). Kulttuuriset arvo-orientaatiot: kansallisten erojen luonne ja seuraukset. [Cultural Value Orientations: Nature \& Implications of National Differences]. Espoo: Limor kustannus.

Schwartz, S. H., Vecchione, M., Fischer, R., Ramos, A., Demirutku, K., Dirilen-Gumus, O., ... Konty, M. (2012). Refining the Theory of Basic Individual Values. Journal of Personality and Social Psychology, 103, 663-688. 
Seligman, C., Olson, J. M., \& Zanna, M. P. (Eds.) (1996). The psychology of values: The Ontario symposium, 8. Mahwah, NJ: Erlbaum.

Smith, P. B., \& Schwartz, S.H. (1997).Values. In J. W. Berry, M. H. Segall, \& Kagitcibasi C. (Eds.), Social behavior and applications: Vol. III of handbook of cross-cultural psychology ( $2^{\text {nd }}$ ed., pp. 77-118). Boston: Allyn \& Bacon.

Statistics Finland (2006). Suomen tilastollinen vuosikirja 2006 [Statistical Yearbook of Finland 2006]. Hämeenlinna, Finland: Karisto Oy.

Staudinger, U. M., \& Fleeson, W. (1996). Self and personality in old and very old age: A sample case of resilience? Development and Psychopathology, 8, 867-885.

Staudinger, U. M., Freund, A. M., Linden, M., \& Maas, I. (1999). Self, personality, and life regulation: Facets of psychological resilience in old age. In P. B. Baltes \& K. U. Mayer (Eds.), The Berlin Aging Study: Aging from 70 to 100 (pp. 302-328). New York: Cambridge University Press.

Staudinger, U. M., Smith, J., \& Freund, A. M. (1992). The goal system: A facet of the resilient self in old age? Paper presented at the $25^{\text {th }}$ International Congress of Psychology, Brussels, Belgium, July 1992.

Tucker, L. R., \& Lewis, C. (1973). A reliability coefficient for maximum likelihood factor analysis. Psychometrika, 38(1), 1-10. 
Table 1 Means and Standard Deviations of Schwartz Values: The 57- item Finnish version at Age $50(n=217)$

\begin{tabular}{|c|c|c|c|}
\hline Value & Items & $M$ & $S D$ \\
\hline \multirow[t]{9}{*}{ Universalism } & equality & 4.86 & 1.62 \\
\hline & world at peace & 4.66 & 1.94 \\
\hline & social justice & 5.01 & 1.47 \\
\hline & wisdom & 4.82 & 1.52 \\
\hline & broad-minded & 4.62 & 1.73 \\
\hline & unity with nature & 3.74 & 1.71 \\
\hline & world of beauty & 3.81 & 1.87 \\
\hline & protecting the environment & 4.04 & 1.66 \\
\hline & inner harmony & 5.78 & 1.22 \\
\hline \multirow[t]{9}{*}{ Benevolence } & helpful & 4.56 & 1.42 \\
\hline & forgiving & 4.26 & 1.68 \\
\hline & loyal & 5.21 & 1.43 \\
\hline & honest & 5.65 & 1.24 \\
\hline & responsible & 5.63 & 1.15 \\
\hline & spiritual life & 2.72 & 2.28 \\
\hline & meaningful life & 5.00 & 1.56 \\
\hline & mature love & 5.11 & 1.53 \\
\hline & true friendship & 5.40 & 1.29 \\
\hline \multirow[t]{4}{*}{ Conformity } & politeness & 4.58 & 1.52 \\
\hline & self-discipline & 3.61 & 1.70 \\
\hline & honoring parents and elders & 4.77 & 1.59 \\
\hline & obedient & 4.04 & 1.61 \\
\hline \multirow[t]{5}{*}{ Tradition } & respect for tradition & 2.66 & 1.81 \\
\hline & moderate & 3.56 & 1.55 \\
\hline & humble & 2.15 & 1.94 \\
\hline & accepting my portion in life & 2.59 & 2.04 \\
\hline & devout & 1.03 & 2.09 \\
\hline \multirow[t]{5}{*}{ Power } & social power & 0.74 & 1.61 \\
\hline & wealth & 2.77 & 1.70 \\
\hline & authority & 1.21 & 1.77 \\
\hline & preserving public image & 2.14 & 1.93 \\
\hline & social recognition & 3.14 & 1.87 \\
\hline \multirow[t]{4}{*}{ Hedonism } & pleasure & 3.43 & 1.62 \\
\hline & enjoying life & 4.65 & 1.69 \\
\hline & indulgent & 4.05 & 1.70 \\
\hline & privacy & 4.74 & 1.48 \\
\hline \multirow[t]{6}{*}{ Self-direction } & freedom & 5.10 & 1.57 \\
\hline & creativity & 3.83 & 1.80 \\
\hline & curious & 3.77 & 1.77 \\
\hline & independent & 3.95 & 1.77 \\
\hline & choosing own goals & 3.56 & 1.81 \\
\hline & self-respect & 5.28 & 1.33 \\
\hline \multirow[t]{3}{*}{ Stimulation } & exciting life & 2.71 & 1.54 \\
\hline & varied life & 3.43 & 1.85 \\
\hline & daring & 2.28 & 1.87 \\
\hline \multirow[t]{4}{*}{ Achievement } & ambitious & 3.46 & 1.81 \\
\hline & influential & 2.03 & 1.79 \\
\hline & competent & 4.15 & 1.64 \\
\hline & successful & 3.29 & 1.60 \\
\hline
\end{tabular}




\begin{tabular}{llll} 
& intelligent & 4.47 & 1.43 \\
Security & social order & 4.12 & 1.83 \\
& national security & 4.10 & 2.01 \\
reciprocation of favors & 2.56 & 1.82 \\
family security & 6.51 & 0.87 \\
clean & 4.48 & 1.56 \\
sense of belonging & 4.54 & 1.56 \\
healthy & 5.89 & 1.58 \\
\hline
\end{tabular}

Table 2 Means and Standard Deviations of PLI items at Age $50(n=224)$

\begin{tabular}{lcc}
\hline Variable & & \\
& & $S D$ \\
& 3.83 & 0.90 \\
\hline Health & 3.34 & 1.00 \\
Cognition & 3.42 & 0.96 \\
Leisure & 3.46 & 0.86 \\
Friends & 3.22 & 0.81 \\
Sexuality & 0.78 \\
Family & 4.23 & 1.06 \\
Work & 3.81 & 1.02 \\
Independence & 3.25 & 1.00 \\
Life reflection & 3.43 & 0.93 \\
Death & 2.06 & \\
\hline
\end{tabular}


Table 3 Standardized Factor Loadings and Model Fit Indices of Tested Models of the Structure of Values at Age $50(n=217)$

\begin{tabular}{|c|c|c|c|}
\hline Model & $\begin{array}{l}10 \text { factors, } 57 \text {-item } \\
\text { Finnish version }\end{array}$ & $\begin{array}{l}10 \text { factors, } 46 \text {-item } \\
\text { version }\end{array}$ & $\begin{array}{l}14 \text { factors, } 46 \text {-item } \\
\text { version }\end{array}$ \\
\hline $\begin{array}{l}\text { Chi-Squared test of model fit, } \\
\text { (value) }\end{array}$ & 2762.5 & 1794.9 & 1423.3 \\
\hline Degrees of freedom & 1484 & 944 & 887 \\
\hline RMSEA & .063 & .064 & .053 \\
\hline SRMR & .079 & .075 & .065 \\
\hline Factor and item labels: & Factor loadings: & Factor loadings: & $\begin{array}{l}\text { Factor loadings and sub- } \\
\text { factor labels: }\end{array}$ \\
\hline Universalism & & & Societal concern \\
\hline equality & .547 & .559 & .546 \\
\hline world at peace & .614 & .597 & .717 \\
\hline social justice & .620 & .607 & $\begin{array}{l}.679 \\
\text { Tolerance }\end{array}$ \\
\hline wisdom & .495 & .507 & .554 \\
\hline broad-minded & .406 & .423 & $\begin{array}{l}.599 \\
\text { Protecting nature }\end{array}$ \\
\hline unity with nature & .646 & .643 & .800 \\
\hline world of beauty & .578 & .617 & .578 \\
\hline $\begin{array}{l}\text { protecting the environment } \\
\text { inner harmony }\end{array}$ & $\begin{array}{l}.620 \\
.303\end{array}$ & .613 & .713 \\
\hline Benevolence & & & Caring \\
\hline honest & .506 & .476 & .447 \\
\hline helpful & .675 & .710 & .747 \\
\hline forgiving & .699 & .705 & $\begin{array}{l}.731 \\
\text { Dependability }\end{array}$ \\
\hline loyal & .614 & .621 & .805 \\
\hline responsible & .350 & .360 & .479 \\
\hline spiritual life & .427 & & \\
\hline meaningful life & .467 & & \\
\hline mature love & .507 & & \\
\hline true friendship & .536 & & \\
\hline Conformity & & & \\
\hline politeness & .737 & .733 & .731 \\
\hline self-discipline & .575 & .560 & .562 \\
\hline honoring parents and elders & .736 & .732 & .727 \\
\hline obedient & .705 & .689 & .694 \\
\hline Tradition & & & \\
\hline respect for tradition & .543 & .547 & .557 \\
\hline moderate & .480 & .510 & .509 \\
\hline humble & .634 & .631 & .625 \\
\hline accepting my portion in life & .490 & .532 & .541 \\
\hline being devout & .417 & .419 & .403 \\
\hline Power & & & \\
\hline social power & .593 & .604 & .606 \\
\hline wealth & .620 & .601 & .595 \\
\hline authority & .726 & .767 & .738 \\
\hline preserving public image & .615 & .609 & .634 \\
\hline social recognition & .583 & & \\
\hline
\end{tabular}




\begin{tabular}{|c|c|c|c|}
\hline \multicolumn{4}{|l|}{ Hedonism } \\
\hline pleasure & .679 & .723 & .706 \\
\hline enjoying life & .744 & .718 & .736 \\
\hline indulgent & .795 & .774 & .768 \\
\hline privacy & .418 & & \\
\hline \multicolumn{3}{|l|}{ Self-direction } & Autonomy of thought \\
\hline freedom & .495 & .497 & .279 \\
\hline creativity & .673 & .691 & .686 \\
\hline \multirow[t]{2}{*}{ curious } & .600 & .614 & .650 \\
\hline & & & Autonomy of action \\
\hline \multicolumn{3}{|l|}{ freedom } & .259 \\
\hline independent & .430 & .422 & .489 \\
\hline choosing own goals & .447 & .449 & .538 \\
\hline self-respect & .528 & & \\
\hline \multicolumn{4}{|l|}{ Stimulation } \\
\hline exciting life & .584 & .591 & .590 \\
\hline varied life & .683 & .684 & .685 \\
\hline daring & .840 & .835 & .836 \\
\hline \multicolumn{4}{|l|}{ Achievement } \\
\hline ambitious & .762 & .752 & .754 \\
\hline influential & .727 & .750 & .731 \\
\hline competent & .718 & .667 & .691 \\
\hline successful & .766 & .773 & .773 \\
\hline intelligent & .487 & & \\
\hline \multicolumn{4}{|l|}{ Security } \\
\hline social order & .451 & .383 & .468 \\
\hline national security & .512 & .495 & .545 \\
\hline reciprocation of favors & .505 & .529 & .525 \\
\hline family security & .301 & .299 & .271 \\
\hline clean & .590 & .626 & .565 \\
\hline sense of belonging & .556 & & \\
\hline healthy & .217 & & \\
\hline
\end{tabular}

Note. Factor and sub-factor labels are boldfaced. 
Table 4 Comparison of the Second-Order Value Models’ Fit to the Selected Model (46-Item Version, 14 Value Factors) Using SEM: Standardized Factor Loadings

\begin{tabular}{lll}
\hline Model & Two factors & Four factors \\
\hline RMSEA & .062 & .060 \\
SRMR & .083 & .079 \\
Universalism -societal concern & Social-focused .743 & Self-transcendence .802 \\
Universalism -tolerance & .510 & .695 \\
Universalism -protecting nature & .666 & .725 \\
Benevolence -caring & .853 & .876 \\
Benevolence -dependability & .625 & .655 \\
Conformity & .942 & Conservation .993 \\
Tradition & .842 & .866 \\
Security & .950 & .974 \\
Power & Person-focused .762 & Self-enhancement .884 \\
Achievement & .849 & .868 \\
Hedonism & .666 & Openness to change .654 \\
Self-direction -autonomy of thought & .706 & .818 \\
Self-direction -autonomy of action & .853 & .888 \\
Stimulation & .809 & .859 \\
\hline
\end{tabular}

Note. Second-order value factor models: two-factor model (person- and social-focused dimensions); four-factor model (conservation, openness to change, self-enhancement, and self-transcendence). 
Table 5 Comparison Table of the Selected Confirmatory Model of the PLI Scale at Age 50 (Soul-searching, Basic needs and Pleasure) and Staudinger's (1993) Two-Factor (Obligatory and Optional) Confirmatory Model: Standardized Factor Loadings

\begin{tabular}{|c|c|}
\hline Staudinger's model & 3-factor model \\
\hline & Soul-searching \\
\hline f1 . $65^{* * *}$ & Cognition $.57^{* * *}$ \\
\hline f1 $.52 * * *$ & Independence $.65^{* * *}$ \\
\hline f1 . $.49 * * *$ & Life reflection $.56^{* * *}$ \\
\hline \multirow[t]{2}{*}{ f1 .38*** } & Death $.44^{* * *}$ \\
\hline & Basic needs \\
\hline f2 .26* & Sexuality $.34 * *$ \\
\hline f1 .29** & Family $.80^{* * *}$ \\
\hline \multirow[t]{2}{*}{ f2 .16} & Work .35** \\
\hline & Pleasure \\
\hline f1 $.51 * * *$ & Health $.68^{* * *}$ \\
\hline f2 $.57 * * *$ & Leisure $.56^{* * *}$ \\
\hline f2 $.47 * * *$ & Friends $.41^{* * *}$ \\
\hline
\end{tabular}


Table 6 The PLI Scale's Three Factors in Correlation to Schwartz's 14 Value Factors, and the Model Fit Indices Using RMSEA and SRMR with CFA

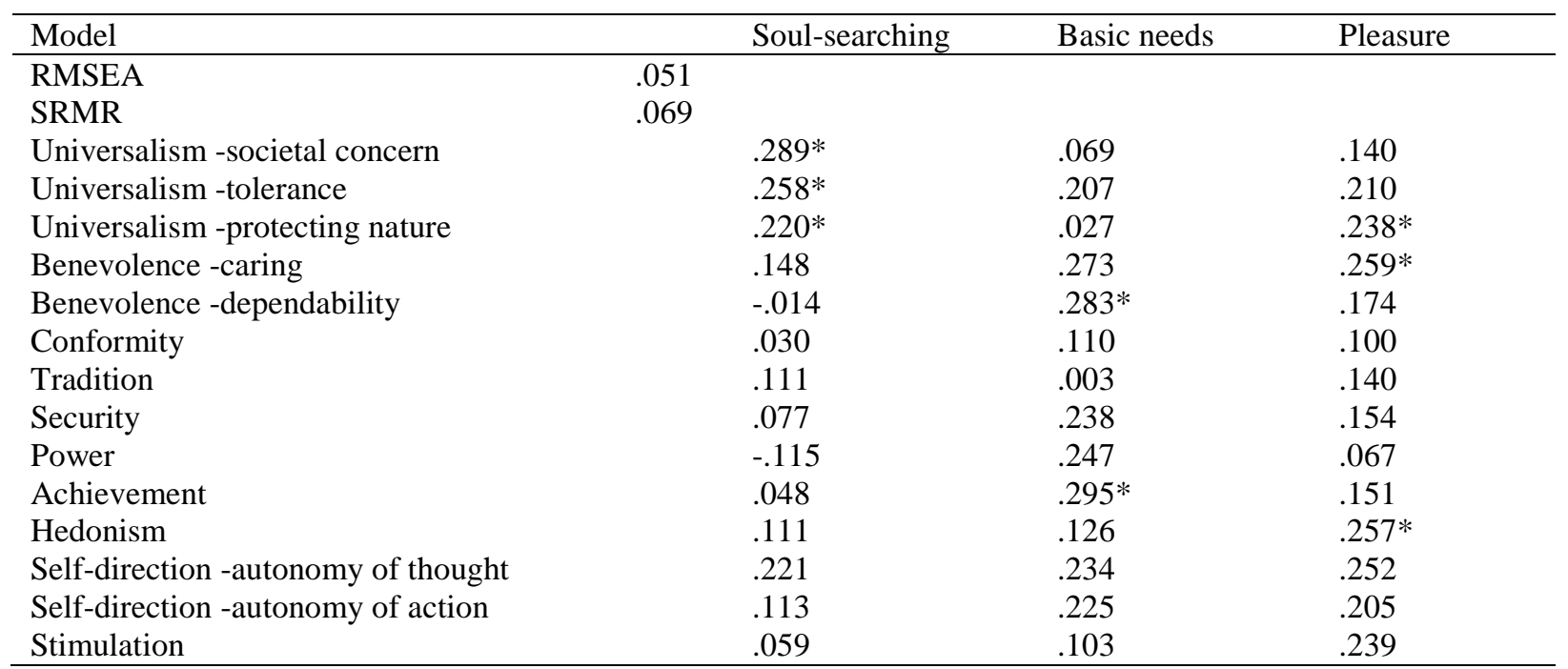

Note. ${ }^{* * *} p<.001 ; * * p<.01 ; * p<=.05$. 
Table 7 Correlations and Model Fit Indices (RMSEA and SRMR) of the PLI Scale’s Three Factors with the Second-Order Four and

Two Factors of Values (from the Latent Higher-Order 14-Value Factor Model with 46 Items) Using SEM

\begin{tabular}{|c|c|c|c|c|c|c|c|c|}
\hline Model & & $\mathrm{f1}$ & $\mathrm{f} 2$ & f3 & & f1 & f2 & f3 \\
\hline RMSEA & .055 & & & & .057 & & & \\
\hline SRMR & .080 & & & & .083 & & & \\
\hline $\begin{array}{l}\text { Self- } \\
\text { transcendence }\end{array}$ & & $.214^{*}$ & .209 & $.270 *$ & Social-focused & .121 & .179 & .186 \\
\hline Conservation & & .054 & .132 & .128 & & & & \\
\hline $\begin{array}{l}\text { Self- } \\
\text { enhancement }\end{array}$ & & -.035 & .277 & .132 & $\begin{array}{l}\text { Person- } \\
\text { focused }\end{array}$ & .060 & .243 & $.225^{*}$ \\
\hline $\begin{array}{l}\text { Openness to } \\
\text { change }\end{array}$ & & .128 & .163 & $.295 *$ & & & & \\
\hline
\end{tabular}

Note. Second-order four-factor model: self-transcendence (universalism-societal concern, universalism-tolerance, universalism-protecting nature, benevolencecaring, benevolence-dependability); conservation (conformity, tradition, security); self-enhancement (power, achievement); openness to change (hedonism, selfdirection-autonomy of thought, self-direction-autonomy of action, stimulation). Second-order two-factor model: social-focused dimension (universalism- societal concern, universalism-tolerance, universalism-protecting nature, benevolence-caring, benevolence-dependability, conformity, tradition and security); personfocused dimension (power, achievement, hedonism, self-direction-autonomy of thought, self-direction-autonomy of action, stimulation). Soul-searching = f1, basic needs $=\mathrm{f} 2$, pleasure $=\mathrm{f} 3$. *** $p<.001 ; * * p<.01 ; * p<=.05$. 